\title{
Evaluation of Patients with Delirium in the Emergency Department
}

\author{
Latif Duran, Dursun Aygün \\ Department of Emergency Emergency Medicine, Ondokuz Mayıs University, Samsun, Turkey
}

\section{ABSTRACT}

Objective: Delirium is a neuropsychiatric syndrome characterized by acute onset and a fluctuating course of globally altered mental status. It has been reported that the frequency of delirium among patients hospitalized with any disorder ranges from 2 to $30 \%$. However, in the literature, few studies have evaluated the frequency of delirium in hospitalized patients, including those older than 65 years. According to our knowledge, this is the first study on adult patients in all age groups in an emergency department. We aimed to classify delirium according to its etiological causes and to compare the age groups for frequency and these causes.

Material and Methods: Forty-three patients were included in the study; they had been diagnosed with delirium according to the Diagnostic and Statistical Manual of Mental Disorders (DSM)-IV in an emergency department from December 2002 to December 2003. The patients were divided into two groups (group I: age < 65 years, group II: age $\geq 65$ years). Following a detailed history, each patient underwent a physical and neurological examination. Additionally, the Mini-Mental State Examination was administered. Radiological and hematological examinations were conducted on all patients who had indications for such testing.

Results: Of the patients with delirium, 18 were female and 25 were male. Mean age was 61.18 years (range 18 to 90 years). Of the 43 patients, 21 were in group I and 22 were in group II. The most common causes of delirium were metabolic disorders. There was no significant difference between group I and II for the frequency or etiological causes of delirium.

Conclusion: In emergency departments, all patients with delirium should be evaluated for etiological factors, especially metabolic disorders, as treatment of the underlying cause is essential in delirium.

Key Words: Emergency department, delirium, etiology, age groups

Received: 29.12.2011

Accepted: 12.03.2012

\section{Introduction}

Delirium is a neuropsychiatric syndrome that begins acutely with an undulant progression. It is characterized by global mental alterations, particularly corruption in attention (1-5). It is known that delirium is an independent indicator for poor prognosis in older patients in the hospital (6). Death may occur if an early diagnosis cannot be made and the underlying cause cannot be treated. Thus, in patients with delirium, early diagnosis and treatment of the underlying cause is very important. In clinical practice, it has been reported that delirium is frequently misdiagnosed by physicians; the rate of misdiagnosis is approximately $33-66 \%(1-5)$.

Delirium may occur due to many pathological situations $(1,5)$. It is known that patients older than 65 years have a greater tendency to experience delirium. Most studies on delirium have focused on patients 65 years and older. On the other hand, the majority of studies have focused on hospitalized patients. Studies on patients with delirium in the emergency department (ED) are extremely rare (7). To our knowledge, this is the first study of delirium performed in the ED that has compared patients under and above 65 years. The aim of this study was to evaluate patients with delirium in the ED for the incidence of etiological factors.

\section{Material and Methods}

This study was performed from December 2002 to December 2003 in the Ondokuz Mayıs University ED with permission of the Ethical Committee.

In the ED, patients with a diagnosis of delirium according to the diagnostic criteria of the Diagnostic and Statistical Manual of Mental Disorders (DSM)-IV were investigated by an emergency medical resident and a neurologist (8). Alterations in the mental status of patients were determined by the Mini-Mental State Examination (MMSE) (9). All patient scores were recorded. Diagnoses of depression and dementia were made according to medical history. Differential diagnoses of delirium from primary psychosis, dementia and depression were made according to the clinical features. To determine the etiological factors of delirium, a detailed anamnesis was obtained from the relatives of the patients. In the anamnesis, the patient's history of drug and alcohol use, systemic illnesses, non-organic psychotic disorders, trauma, dementia and previous epileptic seizures were assessed. Complaints on admission were recorded. Detailed physical and neurological examinations were performed for all patients. 
The inclusion criteria for our study were as follows: 1) presence of delirium with onset upon admission or during followup in the ED, 2) correspondence with the DSM-IV criteria for delirium and 3 ) adult patients (older than 18 years). Patients with delirium tremens and mental retardation were excluded.

Blood analysis, urine analysis, radiological studies, electrocardiographic (ECG) and ultrasonography (USG) findings as well as clinical findings corresponding to delirium criteria were recorded on private study charts. In the presence of focal neurological findings or symptoms (facial asymmetry, hemiparesis/hemiplegia, presence of pathological reflexes), a history of head trauma, recurrent epileptic seizures or a history of therapy for an intracranial lesion (surgery or radiotherapy), patients underwent neuroimaging (computed tomography [CT] or magnetic resonance imaging [MRI]) after stabilization.

Etiological factors for delirium were classified into three categories: structural lesions, metabolic-systemic disorders and undiagnosed etiology. Diagnoses of structural lesions were made according to the neuroimaging findings. Diagnoses of metabolic-systemic disorders were made through the absence of structural lesions in imaging studies and the presence of abnormal metabolic-systemic findings. Usage of more than two drugs was considered multiple medication history (polypharmacy). In the blood-gas analysis, partial oxygen pressure less than $60 \mathrm{mmHg}$ and partial carbon dioxide pressure more than $50 \mathrm{mmHg}$ was considered to indicate hypoxia. When no etiological factors could be determined, patients were classified as having an undiagnosed etiology. In this study, patients were divided into two groups according to their age distribution (group I: age $<65$ years, group II: age $\geq 65$ years).

The data were reported as mean \pm standard deviation if they were normally distributed. The Kolmogorov-Smirnov test was used to compare etiological factors according to age group. Chi-square analysis was performed to evaluate the frequency of hallucinations and etiological factors. Student's t-test was used to compare vital signs between groups. A p value $<0.05$ was taken as statistically significant.

\section{Results}

In a one-year period, 43 patients fit the DSM-IV criteria for delirium. Of these patients, $42 \%(n=18)$ were female and the mean age was 61.2 years. The demographic features of the patients are summarized in Table 1.

In 35 patients (81\%), a metabolic-systemic cause was determined, and in five patients $(12 \%)$ a structural cause of delirium was found. There were only three patients with an undiagnosed etiology. The most common etiological factors were metabolic-systemic reasons $(p<0.05)$. Of the patients with structural lesions, two had acute ischemic stroke, one had a subdural hematoma, one had sinus venous thrombosis and one had a brain tumor. When compared according to the etiological factors, there was no significant difference between group I and II ( $p>0.05)$. The distribution of etiological factors in patients with delirium is shown in Table 2 according to age group.

Of the patients with systemic-metabolic etiology, 18 were included in group I and 17 were included in group II. The most frequent metabolic-systemic causes were drug intoxication, electrolyte disorders and hypoxia. Six patients (17\%) had drug intoxication and five of them were in group II. Electrolyte disturbances were found in eight patients (24\%). Of these, three were included in group I (38\%). Hypoxia was determined in six patients, and all of these patients were in group II. Hypoxia was associated with carbon monoxide poisoning, chronic obstructive pulmonary disease (COPD), heart failure, myocardial infarction (MI), arrhythmia and lung cancer. The distribution of the etiological factors of the cases is shown in Table 3.

When the vital signs of patients were investigated upon admission, in terms of systolic and diastolic mean arterial blood pressure, pulse rate and mean body temperature, there were no statistically significant differences between the two groups ( $p>0.05$ ) (Table 4 ).

Hallucinations were found in 35 patients (81\%). Visual hallucinations were observed in 25 (58\%), auditory hallucinations

Table 1. The distribution of demographic characteristics of patients according to age group

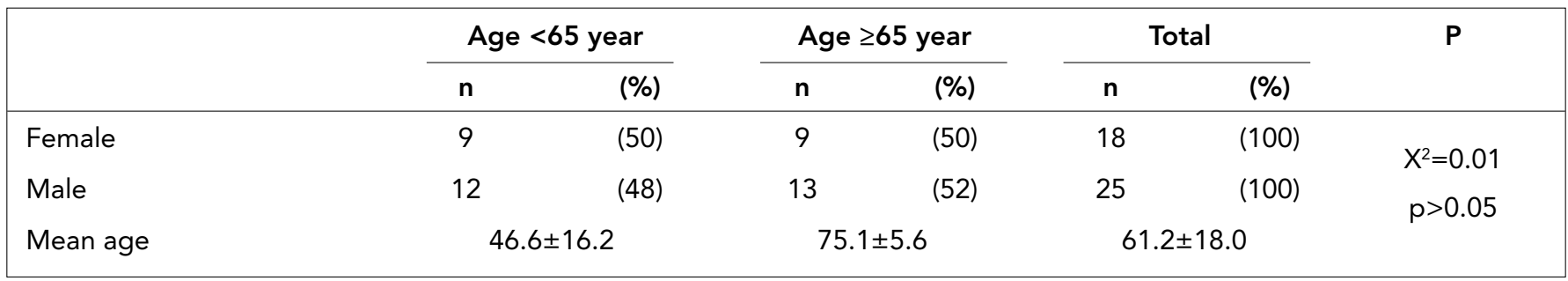

Table 2. The distribution of patients with delirium according to etiology

\begin{tabular}{|c|c|c|c|c|c|c|c|}
\hline \multirow[b]{2}{*}{ Etiology } & \multicolumn{2}{|c|}{ Age $<65$ year } & \multicolumn{2}{|c|}{ Age $\geq 65$ year } & \multicolumn{2}{|c|}{ Total } & \multirow[t]{2}{*}{$\mathbf{P}$} \\
\hline & $n$ & $(\%)$ & $n$ & (\%) & $\mathrm{n}$ & (\%) & \\
\hline Metabolic Causes & 17 & (49) & 18 & $(51)$ & 35 & $(100)$ & \multirow{3}{*}{$\begin{array}{l}X^{2}=44.8 \\
p<0.05\end{array}$} \\
\hline Structural Causes & 3 & $(60)$ & 2 & $(40)$ & 5 & $(100)$ & \\
\hline Undiagnosed etiologies & 1 & (33) & 2 & (67) & 3 & $(100)$ & \\
\hline
\end{tabular}


Table 3. Etiological factors for delirium according to age group

\begin{tabular}{|c|c|c|c|c|c|c|}
\hline \multirow[b]{2}{*}{ Etiological factors } & \multicolumn{2}{|c|}{ Age <65 year } & \multicolumn{2}{|c|}{ Age $\geq 65$ year } & \multicolumn{2}{|c|}{ Total } \\
\hline & $\mathbf{n}$ & (\%) & $\mathrm{n}$ & (\%) & $\mathbf{n}$ & (\%) \\
\hline Structural causes & 3 & (60) & 2 & (40) & 5 & $(100)$ \\
\hline Ischemic infarct & 1 & $(20)$ & 1 & (20) & 2 & $(40)$ \\
\hline Subdural hemorrhage & 1 & $(20)$ & - & $(-)$ & 1 & (20) \\
\hline Sinus venous thrombosis & 1 & $(20)$ & - & $(-)$ & 1 & (20) \\
\hline Tumor & - & $(-)$ & 1 & (20) & 1 & (20) \\
\hline Metabolic causes & 18 & $(51)$ & 17 & (49) & 35 & $(100)$ \\
\hline Hyperglycemia & 3 & (9) & - & $(-)$ & 3 & (9) \\
\hline Hypoglycemia & 1 & (3) & - & $(-)$ & 1 & $(3)$ \\
\hline Uremia & - & $(-)$ & 4 & (10) & 4 & $(10)$ \\
\hline Hypernatremia & - & $(-)$ & 1 & (3) & 1 & (3) \\
\hline Hyponatremia & 2 & (6) & 3 & (9) & 5 & (15) \\
\hline Hyperkalemia & 1 & (3) & 1 & (3) & 2 & (6) \\
\hline Alcohol intoxication & 1 & (3) & - & $(-)$ & 1 & (3) \\
\hline Polypharmacy & - & $(-)$ & 1 & (3) & 1 & (3) \\
\hline Drug intoxication & 5 & (14) & 1 & (3) & 6 & $(17)$ \\
\hline Hypoxia & - & $(-)$ & 6 & $(17)$ & 6 & $(17)$ \\
\hline Liver failure & 3 & (9) & - & $(-)$ & 3 & (9) \\
\hline Fever* & 2 & (6) & - & $(-)$ & 2 & (6) \\
\hline Undiagnosed etiologies & 1 & (33) & 2 & $(67)$ & 3 & $(100)$ \\
\hline
\end{tabular}

Table 4. Vital signs of patients upon admission according to age group

\begin{tabular}{|c|c|c|c|c|}
\hline & & $\begin{array}{l}\text { Age } \\
<65 \text { year }\end{array}$ & $\begin{array}{c}\text { Age } \\
\geq 65 \text { year }\end{array}$ & $p$ \\
\hline \multirow{2}{*}{$\begin{array}{l}\text { Blood pressure } \\
(\mathrm{mmHg})\end{array}$} & Systolic & $138 \pm 26$ & $146 \pm 30$ & \\
\hline & Diastolic & $83.1 \pm 15$ & $88.0 \pm 19$ & \\
\hline $\begin{array}{l}\text { Pulse } \\
\text { (beat/min) }\end{array}$ & & $93 \pm 27$ & $90 \pm 12$ & \\
\hline \multirow[t]{2}{*}{ Fever $\left({ }^{\circ} \mathrm{C}\right)$} & & $36.5 \pm 0.9$ & $36.6 \pm 0.7$ & \\
\hline & & & & $>0.05$ \\
\hline
\end{tabular}

in three (7\%) and mixed hallucinations in seven patients (16\%). Visual hallucinations were found to be significantly more common $(p<0.05)$. In the patients with visual hallucinations, 23 (92\%) had metabolic causes, one (4\%) had structural lesions and one (4\%) had an undiagnosed etiology. Of the patients with visual hallucinations, $13(52 \%)$ were over 65 years of age. A structural lesion was determined in one of three patients who had auditory hallucinations, and a metabolic cause was determined in one patient. In the last patient, no etiological factor could be determined. One of the three patients with auditory hallucinations was under 65 years of age. In patients with mixed hallucinations, a structural lesion was found in
Table 5. The distribution of MMSE score according to age and gender

\begin{tabular}{|c|c|c|c|c|}
\hline & \multicolumn{2}{|c|}{ Gender } & \multicolumn{2}{|c|}{ Age Group } \\
\hline & Female & Male & $\begin{array}{c}\text { Age } \\
<65 \text { year }\end{array}$ & $\begin{array}{c}\text { Age } \\
\geq 65 \text { year }\end{array}$ \\
\hline $\begin{array}{l}\text { MMDD } \\
\text { test score } \\
\text { (Mean } \pm \text { SD) }\end{array}$ & $9.6 \pm 5$ & $12.6 \pm 4$ & $12.6 \pm 5$ & $10.1 \pm 4$ \\
\hline$p$ value & \multicolumn{2}{|c|}{$>0.05$} & \multicolumn{2}{|c|}{$>0.05$} \\
\hline
\end{tabular}

two patients $(29 \%)$ and a metabolic cause was found in five patients $(71 \%)$. There was no significant difference between age groups $(p>0.05)$ in terms of the type of hallucinations. There was also no statistically significant difference between age and gender groups according to the MMSE test scores ( $p>0.05$ ) (Table 5).

When probable risk factors were evaluated, $14 \%(n=6)$ of the patients had depression. All the patients with depression were under 65 years of age. Upon admission, eight (19\%) of the patients had fever; of these, four (50\%) were under 65 years. There was no significant difference between groups according to the frequency of fever $(p>0.05)$. A history of epileptic seizure was present in three cases (7\%). In patients with a history of epileptic seizure, two had a structural lesion and one had a metabolic disorder. 
Nine patients (21\%) had dementia; one of these (11\%) was in group I. According to dementia frequency, there was a significant difference between age groups $(p<0.05)$. In four patients, there was a history of cerebrovascular disease.

Eight of the patients had diabetes mellitus (DM). Of these, five were in group I and three were in group II. Four patients had cancer, three had COPD, 17 had heart disease and four had chronic renal failure.

\section{Discussion}

The present study is the first to investigate patients with delirium by dividing them into two groups according to age (group I <65 years, group II $\geq 65$ years). Furthermore, only a few studies have investigated delirium patients in the $\operatorname{ED}(7,10-12)$, and in previous studies, all patients were older than 65 years. In our study, delirium was seen in $0.5 \%$ of patients admitted to the ED.

Elie et al. (7) reported that the prevalence of delirium in emergency patients older than 65 years is $9.6 \%$. However, the patient population and methods in their research were different from those in our study. When patients did not correspond to the DSM-IV criteria, a diagnosis of probable delirium was made. In another study, the prevalence of delirium in older patients in the ED was reported to be $5 \%$ (12). However, this study had a retrospective design. Other studies on delirium in older patients in the ED revealed a prevalence of $10-17 \%$ $(10,11)$.

Our study was designed prospectively and methods for definite diagnosis were used. Although patients older than 65 years were identified as having the greatest risk of delirium, we did not find a significant difference between age groups according to delirium frequency $(13,14)$. In our study, the most common cause of delirium was determined to be metabolic disorders; metabolic-systemic disorders were found in $81 \%$ of the patients. These results are compatible with the literature $(1,4,15)$. There was no significant difference in the metabolic causes of delirium between age groups. Electrolyte abnormalities were the most common cause of systemic-metabolic disorders. Fluid-electrolyte abnormalities were found in $19 \%$ of our patients. The relationship between acute stroke and delirium is also well-known. It has been reported that delirium may be a non-specific finding of acute stroke, and may also occur due to the area of the brain affected by the stroke $(1,16)$. In $5 \%$ of our patients, acute stroke was the reason for delirium. Patients with acute stroke were divided equally into the two groups. In these patients, there was a relationship between the location of the lesion and delirium (16).

Of our patients, $9 \%$ had a history of stroke and $75 \%$ of these were in group II (over 65 years). Other structural lesions found in the present study were subdural hematoma $(n=1)$, sinus venous thrombosis $(n=1)$ and tumor $(n=1)$.

It has been reported that dementia is present $81 \%$ of the time in cases of delirium (17). In our study, $21 \%$ of the patients had dementia; of these, $89 \%$ were older than 65 years. Patients with psychiatric disorders tend to be more likely to develop delirium $(1,16)$. For example, it has been reported that
$42 \%$ of older patients with depression develop delirium (1). In this study, depression was identified in $14 \%$ of our patients, and all of these were included in the younger age group. In all of these cases, delirium had developed due to a metabolic cause.

It has been reported that male gender is associated with a higher risk of delirium development than female gender $(4,18)$. In our study, $58 \%$ of the patients with delirium were male. However, there was no statistically significant difference between genders according to delirium frequency. Previous studies have also reported that fever is an important risk factor for patients with delirium $(1,18,19)$. In a study with an older patient population, fever or hypothermia was determined in $89 \%$ of patients (18). In our study, fever was observed in $19 \%$ of the patients, and there was no significant difference between age groups according to fever frequency. The most common cause of fever is infection (1). However, in our study, isolated fever was associated with other causes to a greater extent than infection. It has been reported that the most common causes of infection in patients with delirium are urinary tract infections, pneumonia and septicemia (1). In a study with an older patient population, infection was determined in $35 \%$ of cases (6). In another study, this proportion was $8 \%(15)$. Although infection was identified in $28 \%$ of patients with delirium in our study, delirium was found to be associated with multiple etiological factors.

A history of DM was found in $19 \%$ of our cases. Three of the patients with diabetes had hyperglycemia, and one of them had hypoglycemia. Cardiac disease was identified in $40 \%$ of our patients, and the proportion was significantly higher in the older group. These results reveal that the older patient population with cardiac disease should be carefully followed for the development of delirium in the ED. These diseases may cause delirium due to hypoxia. COPD was identified in 7\% of the patients with delirium, and all of these were older patients. Drug intoxication was a cause of delirium in $14 \%$ of the patients. Of those, $83 \%$ were under 65 years of age. The majority of these patients were exposed to drugs through attempted suicide. Nevertheless, all the patients with multiple medications were older than 65 years. These results corresponded with the literature $(1,13,14)$.

In summary, although a difference between age groups was revealed in relation to some etiological factors, in general, the frequencies of metabolic-systemic disorders and structural lesions were similar in both age groups. Cognitive and behavioral symptoms in delirium may be associated with disorders in conduction and neuronal circuits in the brain, depending on the various etiological reasons for these symptoms $(1,13)$. It has been reported that these structures (brainstem, neocortex, hippocampus, frontal [prefrontal] and temporal lobes) are associated with alterations in consciousness level, memory disorders, behavioral alterations and emotional alterations, respectively (1). As a result, etiological factors reveal the symptoms of delirium by affecting these areas, either through direct effects (by affecting neuronal conduction or damaging neurons) or causing functional disturbances in these areas (by affecting neuronal transmission or the functions of neurotransmitters). 
It is obvious that disturbances in cholinergic function are very important in delirium (16). In fact, this system may be associated with the effect of anticholinergic drugs that give rise to the symptoms of delirium. This is supported by the finding that cholinergic function-improving drugs improve behavioral disorders at the same time $(16,20)$.

\section{Conclusion}

While the most common cause of delirium in the ED was metabolic-systemic disorders, the frequency of such disorders and structural lesions were similar in the two age groups. Thus, all patients with delirium in the ED should be investigated for etiology, particularly metabolic causes.

\section{Conflict of Interest}

No conflict of interest was declared by the authors.

\section{References}

1. Ashla MFM. Delirium. In: Bradley WG, Daroff RB, Fenichel GM, Marsden CD, (eds.), Neurology in clinical practice, Boston; Butterworth - Heinemann, 2000.pp.25-36.

2. Bronwn TM, Boyle MF. ABC of psychological medicine: Delirium. BMJ 2002;325:644-7. [CrossRef]

3. David JM. Delirium: optimising management. BMJ 2001;322:144-9. [CrossRef]

4. Inouye SK. The Dilemma of delirium: Clinical and research controversies regarding diagnosis and evaluation of delirium in hospitalized elderly medical patients. Am J Med 1994;97:278-88. [CrossRef]

5. Wahlun L, Björlin GA. Delirium in clinic practice: experiences from a specialized delirium word. Demend Geriatr Cogn Disord 1999;10:389-92. [CrossRef]

6. O'Keefe S, Lavan J. The prognostic significance of delirium in older hospital patients. J Am GS 1997;45:174-8.
7. Elie M, Rousseau F, Cole M, Primeau F, Cusker JM, Bellavance F. Prevalance and detection of delirium emergency depertment patients. CMAJ 2000;163:977-81.

8. American Psychiatric Association. Diagnostic and Statistical Manual of Mental Disorders.(DSM-IV-TR), 4th edn. Washington, DC: American Psychiatric Association, 2000.

9. Huff JS. Alterd mental status and coma. In: Tintinalli JE, Kelen GD, Stapczynski JS (eds.), Emergency medicine: A comprehensive study guide. New york; Mc Graw-Hill, 2000.pp.1440-3.

10. Naughton BJ, Moran MB, Kadah $\mathrm{H}$, Heman-Ackah $\mathrm{Y}$, Longano J. Delirium and other cognitive impairment in older adults in an emergency department. Ann Emerg Med 1995;25:751-5. [CrossRef]

11. Lewis LM, Miller DK, Morley JE, Nork MJ, Lasater LC. Unrecognized delirium in ED geriatric patients. Am J Emerg Med 1995;13:142-5. [CrossRef]

12. Wofford J, Loehr L, Schwartz E. Acute cognitive impairment in elderly ED patients: etiologies and outcomes. Am J Emerg Med 1996;14:649-53. [CrossRef]

13. Lipowski ZJ. Delirium acute confusional states. Toronto Universty press; Toronto, 1989.

14. Jacobson SA. Delirium in the elderly. Psychiatr Clin N Am 1997;20:91-110. [CrossRef]

15. Schuurmans MJ, Duursma SA, Shortridge-Baggett LM. Early recognition of delirium: review of the literature. J Clin Nurs 2001;10:721-9. [CrossRef]

16. Ferro JM, Caeiro L, Verdelho A. Delirium in acute stroke. Curr Opin Neurol 2002;15:51-5.

17. Trzepact PT. Delirium: Advances in diagnosis, pathophysiology, and treatment. Psychiatr Clin North Am1996;19:429-48.

18. Schor JD, Levkoff SE, Lipsitz LA, Reilly $\mathrm{CH}$, Cleary PD, Rowe JW, et al. Risk factors for delirium in hospitalized elderly. JAMA 1992;267:827-31. [CrossRef]

19. Francis J, Martin D, Kapoor WN. A prospective study of delirium in hospitalized elderly. JAMA 1990;263:1097-101. [CrossRef]

20. Bullock R. The clinical benefits of rivastigmin may reflect its dual inhibitory mode of action-ahypothesis. In: J Clin Pract 2002;56:206-14. 